DOCTRINA

\title{
Criminalización de la colusión y delación compensada: Elementos para un análisis riguroso de la persecución penal de carteles
}

\author{
Criminalization of Collusions and Leniency Policies: Elements for a \\ rigorous analysis of criminal prosecution of cartels
}

\section{Agustín Walker Martínez (D) \\ Universidad de Chile}

\begin{abstract}
RESUMEN Últimamente, se ha renovado una discusión frecuente en nuestro sistema penal y de libre competencia: ¿Quién debe ejercer la acción penal en casos de colusión y por qué? En una discusión tan relevante es importante analizar la regulación existente luego de la promulgación de la Ley 20.945 y por qué se legisló de la manera en que se hizo. Este trabajo constituye una aproximación analítica al título V del Decreto Ley 211 introducido por esa ley, a su historia, tensiones y contexto. La idea es destacar los aspectos más relevantes de la criminalización de la colusión, analizando la pertinencia y conveniencia de la sanción penal e intentando dar luces acerca de las características de la regulación adoptada y de su razón de ser, con el objetivo de colaborar en dotar de contenido y perspectiva una discusión a veces cargada de consignas poco rigurosas. Para esto, la pretensión de este trabajo es efectuar un análisis de la decisión adoptada por el legislador en la Ley 20.945, analizando los fundamentos teóricos y prácticos que rodean la discusión relativa a la conveniencia de la criminalización de la colusión. Junto con ello, este artículo busca dar luces acerca de los principales elementos que deben ser tenidos en consideración a la hora de analizar la criminalización de los acuerdos colusorios, otorgando un panorama global de la situación al lector. Bajo ese prisma, analizaremos el tipo penal adoptado con sus distintos componentes, contrastándolo con las decisiones adoptadas en derecho comparado y revisaremos luego los principales aspectos del diseño institucional por el que el legislador chileno optó, intentando relevar los principales puntos de conflicto del mismo, especialmente en cuanto al ejercicio de la acción penal.
\end{abstract}

PALABRAS CLAVE Colusión, sanción penal, historia de la ley, acción penal, delación compensada. 


\begin{abstract}
Who should exercise criminal action for collusion cases and why? This question - already frequent in our penal and competition system - has been further renewed during previous months' debates. For such a relevant discussion, it seems of the utmost importance to analyse, the current regulations after bill 20.945 as well as to wonder why legislation was done in such a manner. This work constitutes an analytical approach to Chile's 211 Law Decree's fifth title, which has been introduced by this law, along with its history, tensions and context. Specifically, the purpose of this work is to highlight the most critical aspects of collusion criminalization by analyzing criminal sanctions pertinence and convenience. Further on, it attempts to do so while endeavoring to enlighten the main characteristics of the implemented regulation - and its purpose- with the intention of contributing with both content and perspective as a way of collaborating to a debate that appears to be sometimes filled with rather ineffective slogans. Indeed, for achieving such a purpose, this work pretends to analyze the legislator's adopted decision on the 20.945 bill, analyzing both theoretical and practical fundamentals around the debates on collusion criminalization's convenience. Additionally, the article looks to identify the main elements to be considered when analyzing the criminalization of collusive agreements, allowing the reader to grasp a wide global perspective of the situation. Bearing this in mind, the article analyses the adopted criminal type - with its different components- contrasting it with the decisions taken in comparative law. Later, it reviews the main institutional design criteria taken by Chile's legislator, an endeavor through which is attempts to reveal its most relevant conflict points, especially regarding the exercise of criminal action.
\end{abstract}

KEYWORDS Collusion, criminal sanction, history of the law, criminal action, leniency policies.

\title{
Introducción
}

El 30 de agosto de 2016 se publicó la Ley 20.945, que introduce un conjunto de medidas destinadas a perfeccionar el modelo de libre competencia. Esta ley, entre otras cosas, agregó un nuevo título $\mathrm{V}$ al Decreto Ley 211, en que se tipifica como delito la colusión en un nuevo artículo 62 del Decreto, que ha suscitado un conjunto de tensiones institucionales y de controversias sociales.

Todo esto implicó que los asuntos constitutivos de colusión dejarían de ser vistos exclusivamente por el Tribunal de Defensa de la Libre Competencia (TDLC), agregándose una arista criminal para perseguir penalmente a las personas naturales por su participación punible en la celebración, organización o ejecución de un acuerdo colusorio. Con esto, se abandonó la noción de que solo se aplicarán multas a las empresas y personas por estos ilícitos, pasando a considerar sanciones privativas de libertad de hasta los diez años de presidio.

Lo anterior fue una decisión polémica y criticada por quienes señalan que la introducción de esta arista penal solo llevaría a detectar menos carteles al impedir que opere el mecanismo de delación compensada de manera adecuada. 
Junto con ello, la modificación trajo consigo la discusión sobre cuál era el mecanismo más idóneo para compatibilizar la capacidad técnica de la Fiscalía Nacional Económica (FNE) y la potestad investigativa del Ministerio Público (MP) como ente que dirige, de manera exclusiva, la investigación penal y ejerce la acción penal.

En relación con esto último, en la Ley 20.945 el legislador se decidió por un diseño institucional que permite la persecución penal solo cuando exista sentencia condenatoria ejecutoriada del TDLC que se inicia exclusivamente por querella interpuesta por la FNE a criterio exclusivo del Fiscal Nacional Económico, siendo facultativo, excepto en casos que comprometan gravemente la libre competencia en los mercados. Por tanto, el Ministerio Público solo podrá comenzar a investigar una vez que dicha querella haya sido interpuesta por parte de la FNE. Esta última decisión se ha mantenido como una polémica de constante tensión entre dichos organismos. ${ }^{1}$

La pretensión de este artículo es reconstruir el conjunto de argumentos jurídicos, políticos y económicos que se entrelazan en la criminalización de la colusión con el objeto de situar una discusión en un contexto doctrinario, jurídico y político, que permita testear el contenido y la racionalidad de la legislación poniendo el énfasis en la necesidad de abordar la arista penal en estos casos con cautela velando siempre por el resguardo de la delación compensada como herramienta, ya que sin esta no se descubren carteles ni se sanciona a los responsables.

Para esto, el trabajo analiza, por un lado, los argumentos que avalan la criminalización de la colusión y, por otro, aquellos que desaconsejan esa idea, con el objetivo de obtener un panorama general que permita al lector formarse una opinión al respecto. Junto con esto, este trabajo busca describir los aspectos más relevantes del nuevo título V del Decreto Ley 211 y, por otro lado, efectuar un análisis crítico de esta nueva normativa para contribuir en un asunto que está recién comenzando.

\section{Criminalización de la colusión}

En la normativa incorporada por medio de la Ley 20.945 confluyeron diferentes argumentos e ideas de carácter jurídico, económico y político que rodean el asunto de la criminalización de la colusión. El tema central se refiere a la pertinencia y conveniencia de incluir un enforcement penal en la lucha contra la colusión, que fue un tema que se debatió intensamente a nivel doctrinal y que permeó la discusión parlamentaria.

1. «FNE rechaza traspasar al Ministerio Público la acción penal en casos de colusión», Diario Financiero, disponible en bit.ly/38nFTFf. 


\section{¿Por qué criminalizar la colusión? Argumentos a favor y en contra}

La pregunta que surge es por qué era necesario un delito de colusión si es que los carteles ya eran detectados y desbaratados por la vía del sistema especializado a cargo de la FNE y el TDLC. Además, otra duda es si es que este delito existió desde 1959 hasta 2003 y nunca se condenó a nadie.

La discusión fundamental se produjo, por un lado, entre quienes sostenían que el sistema de libre competencia ya funcionaba y contaba con los mecanismos tanto disuasivos como represivos suficientes sin que la sanción penal pudiese cumplir un rol relevante en dicha lucha, pudiendo incluso ser contraproducente (Bascuñán, 2015: 8-9) y, por el otro lado, entre quienes sostenían que la gravedad de la conducta colusoria la hacía merecedora de aquel reproche más significativo contenido en nuestra legislación, a saber, la pena privativa de libertad, con una finalidad tanto disuasiva como comunicadora de un reproche jurídico-social.

Han sido varios los argumentos que se han esgrimido para fundamentar la inclusión de la sanción penal:

En primer lugar, en abstracto, se ha discutido bajo qué funciones o fines de la pena se sustentaría la criminalización de la colusión. En ese marco, Peter Whelan (2013: 537) ha elaborado nociones básicas, señalando que:

Claramente, tanto la «rehabilitación por medio del encarcelamiento» como la «neutralización por medio del encarcelamiento» son inapropiadas en este contexto [...]. En contraste, las teorías de la disuasión y retribución, son obviamente más relevantes en el debate sobre la criminalización de la colusión. ${ }^{2}$

De esta manera, la justificación bajo argumentos disuasivos implicaría que:

Los partidarios de la criminalización de la colusión han construido generalmente sus argumentos procriminalización en base a la teoría de la disuasión. La clave de una política efectiva de enforcement anticolusión, argumentan, sería la existencia de una sanción individual de encarcelamiento no indemnizable (Whelan, 2013: 540).

Lo anterior «mandaría un mensaje a los demás ejecutivos sobre los riesgos involucrados en este tipo de comportamiento» (Whelan, 2013: 541). Por otra parte, existirían también criterios retributivos que fundamentarían la incorporación de una sanción penal, entendiendo que:

El castigo debe justificarse no en referencia a su capacidad para prevenir el crimen futuro, sino porque los seres humanos son responsables por sus acciones y deben por tanto recibir lo que merecen cuando incurren en lo que la sociedad considera como decisiones equivocadas (Whelan, 2013: 543).

2. Las traducciones de este y otros autores angloparlantes son del autor de este artículo. 
En la situación chilena esta discusión surgió entendiendo que, más allá de la eficiencia en la detección de carteles, existiría cierto consenso en que estos actos revisten una gravedad significativa (SCS en causa rol 1746-2010) y merecen un serio reproche jurídico-democrático, pasando a ser sancionado con la pena más enérgica que un sistema jurídico penal contemple.

También se sostiene que existirían fundamentos para incluir una sanción penal también desde un punto de vista disuasivo, ya que la sanción pecuniaria no cumpliría dicha finalidad. De esta manera, se planteó que «la ventaja crucial del encarcelamiento es que es imposible cambiar la pena ex post, y es también más difícil contratar un seguro para compensar el riesgo» (Wils, 2005: 37).

Con respecto a los planteamientos disuasivos, es conveniente considerar la regulación contenida en el artículo 26, letra c), del Decreto Ley 211, que existe desde antes de la entrada en vigencia de la Ley 20.945, y que justamente busca impedir que la persona natural sancionada con multa pueda diluir dicho monto en la empresa en la que trabaja o en otros accionistas. Esta norma impide que las sanciones a personas naturales sean pagadas por los accionistas o los socios, o por otras entidades del grupo empresarial.

Sin perjuicio de esta prohibición legal expresa, el punto central sostenido por los defensores del rol disuasivo de la pena privativa de libertad es que el dinero, en cuanto sanción, tiene un componente no corporal y, por tanto, menos disuasivo que la pena privativa de libertad, ya que esta última sería más de una entidad muy superior al riesgo de multa. Por otro lado, el artículo 26, letra c), no prohíbe que la persona natural pueda contar con un seguro que cubra los gastos derivados de esta sanción pecuniaria, lo que impediría que actúe un fin disuasivo efectivo. Más discutible sería el caso en que sea la empresa la que contrate el seguro que luego puede beneficiar a la persona natural sancionada, situación que debemos entender que cabe dentro de la hipótesis que el artículo 26, letra c), del Decreto Ley 211 busca impedir, ya que indirectamente es la empresa la que está cubriendo el pago de la deuda.

Bajo esa lógica, se argumentaba que la multa no actúa como un disuasivo real para las empresas involucradas en estos acuerdos ilícitos a diferencia de la pena de cárcel (Agostini, 2015: 2), ya que es un costo corporal no traspasable padecido por la persona natural condenada, lo que además se produce en un tipo de ilícito en que existiría un análisis previo de costo-beneficio al actuar.

Estos argumentos disuasivos se han criticado sosteniendo que hay otras sanciones que cumplen la misma labor, como las multas altas para personas naturales (Pellegrini, 2015: 5) o sanciones no monetarias, como órdenes de inhabilitación y/u órdenes punitivas a empresas (Jones y Williams, 2014: 124).

Como respuesta a las críticas al rol disuasivo, se ha sostenido que ninguna otra sanción poseería la naturaleza e intensidad que tiene la pena privativa de libertad en cuanto esta «acarrea, y está diseñada para acarrear, un efecto estigma. El enforcement 
criminal cumple un rol más fuerte en el envío de mensajes o en su función expresiva que los enforcement civiles o administrativos» (Wils, 2005: 6), generando - a juicio de estos autores - un efecto disuasivo sin equivalente. De manera más cruda, otros autores han sostenido que:

Para el empresario, la prisión es el infierno, y el convencional análisis costo-beneficio se viene abajo cuando el costo es la cárcel. La amenaza de la prisión, por tanto, sigue siendo el disuasivo más significativo contra las colusiones (Liman, 1970: 630 y 631; citado en Wils, 2005: 34; Whelan, 2012: 678).

El argumento continúa señalando que el valor disuasivo de las multas es discutible en casos de colusión, ya que el contenido de estas últimas es susceptible de ser traspasado a terceros o tiene una intensidad propia que es manifiestamente inferior ${ }^{3}$ $y$, por tanto, en el análisis costo-beneficio no genera un desincentivo suficiente para coludirse. Esto se relacionaría con el hecho de que las decisiones empresariales como coludirse o no son tomadas de manera racional, y obedecen a un análisis serio de costo-beneficio. Así, «en la libre competencia, la teoría de la prevención resulta especialmente apropiada porque los actores-habitualmente grandes compañías y sus funcionarios son racionales y altamente sofisticados» (Grunberg y Montt, 2017: 311). De la misma manera fue entendido por el legislador en la Ley 20.945 (Biblioteca del Congreso Nacional de Chile, 2018: 32, 136, 140, 558).

Dicha racionalidad también ha sido apreciada en doctrina comparada. Así, vinculando los fines retributivos y preventivos, Peter Whelan (2013: 560) ha sostenido que:

Un punto interesante de contacto existe en las teorías disuasivas y retributivas: la racionalidad [...]. Si quienes se coluden son efectivamente racionales (como asume la teoría económica disuasiva), entonces uno puede construir sólidos argumentos teóricos de por qué quienes se coluden tendrían una intención directa como para sostener reclamos de que dichas personas han violado probadas normas morales (facilitando, por tanto, argumentos de índole retributivos).

Aun cuando todo lo antes señalado con respecto al presunto rol disuasivo de la pena privativa de libertad puede ser especialmente aplicable a delitos que son fruto de un análisis tan racional como la colusión, lo cierto es que no existe evidencia robusta que sustente de manera consistente ese rol disuasivo, siendo un asunto altamente discutido, y existiendo posturas consolidadas que afirman que no es posible dar por acreditado el rol disuasivo del castigo y de la pena privativa de libertad (Levitt, 1996; Centro de Políticas Públicas UC, 2017: 2; Tonry, 2008). Así lo sostuvo durante la tramitación legislativa María Elina Cruz (Biblioteca del Congreso Nacional de Chile,

3. Como sostuvo un ejecutivo afectado por el llamado caso pollos: «Si hay multas, las vamos a pagar, pero las multas dan lo mismo, es el hecho, el nombre». Para más información, véase bit.ly/3oB85uM. 
2018: 134). A esto debe sumarse, como veremos más adelante, que en los casos en que ha disminuido la colusión luego de la introducción de una arista penal no ha sido posible determinar si ello se debe a un éxito de un rol disuasivo o a la incapacidad sobreviniente del sistema de detectar carteles. Mientras este efecto no pueda acreditarse de manera fehaciente, el rol preventivo general negativo de la pena privativa de libertad no puede ser el argumento para sostener la criminalización.

En ese marco, y siguiendo con los argumentos centrales que se han esgrimido para avalar la idea de la criminalización, parte fundamental de estos argumentos se refieren al reproche que emana de la pena: Se ha sostenido que mientras la pena privativa de libertad siga siendo la sanción más gravosa que nuestro sistema jurídico establece, carece de coherencia sistémica que la colusión no sea penada en esos términos por la gravedad de sus efectos (Artaza, 2017: 359), que incluso alcanzan al producto interno bruto nacional (Browning, 1997; Dixon, Gunther y Mahmood, 2001; Yoon, 2004; Bjertnaes, 2007; citados en Agostini, 2015: 2), siendo una conducta que además daña a consumidores, reduce la innovación y afecta la eficiencia en la distribución (Whelan, 2012: 678). Más específicamente, se han sostenido interesantes argumentos de índole retributivo consecuencialista (Mañalich, 2015), en cuanto es una conducta de tanta gravedad (Gagliano y Aracena, 2018: 124) que merece el reproche jurídico-democrático más intenso de nuestro ordenamiento jurídico penal al ser una conducta intolerable (Artaza, 2017: 361-362) para lograr una respuesta estatal consistente en términos comunicativos.

Lo anterior se entiende de mejor manera si concebimos que, bajo dicha noción retributiva consecuencialista, la pena es «una reacción estatal expresiva de desaprobación e indignación en contra de la o las personas a las cuales resulte imputable la realización de esa misma forma de comportamiento» (Mañalich, 2015: 5) que, por tanto, implica una retribución a una conducta que atenta contra aquello que la sociedad considera valores relevantes, vulnerando la libre competencia como bien jurídico tutelado (Gagliano y Aracena, 2018: 134 y 137).

En esta línea:

Si el ordenamiento jurídico de referencia instituye el encarcelamiento como la forma paradigmática de sanción penal, entonces parece inconsistente reconocer en la colusión un atentado particularmente grave y socialmente dañoso contra las bases del tráfico económico y al mismo tiempo impugnar la razonabilidad de su criminalización a través de su penalización con una sanción de encarcelamiento (Whelan, 2012: 678).

Lo anterior, sin duda tiene un contenido eminentemente jurídico penal y políticoinstitucional, que se refiere a dar mayor peso a la reacción estatal-social a modo de reproche que a las razones de eficiencia esgrimidas por quienes abogaban por que la colusión no se tipificara penalmente. Así, quienes defienden esta última postura ar- 
gumentaron por cuarenta años que la colusión fue delito sin que se haya condenado a nadie por este. Contraponen lo anterior al hecho de que, desde que en 2003 se derogó ese tipo penal y se concentró la lucha contra la colusión en el ámbito especializado (FNE, TDLC), se han desbaratado múltiples carteles y se ha sancionado pecuniariamente a los mismos (especialmente desde 2009), elaborando una doctrina especializada sólida y consistente que ha otorgado seguridad jurídica y protección al sistema económico (Biblioteca del Congreso Nacional de Chile, 2018: 60). Así, aun cuando merezca un mayor reproche, la criminalización perdería sentido, ya que dificultaría la lucha real contra la colusión.

En ese contrapeso entre reproche jurídico-democrático y eficiencia, el legislador dio mayor preponderancia a la necesidad de una reacción estatal acorde a la magnitud del delito, pero, como veremos, se preocupó de consagrar un diseño institucional que permita mantener cierta eficacia, sin perjuicio del rol simbólico de la modificación (Gagliano y Aracena, 2018: 124).

En la vereda de los opositores a la criminalización, la razón medular por la que la tipificación no sería deseable se refiere a que esta debilitaría la delación compensada al afectar la previsibilidad y certeza que la herramienta requiere. Esto, ya que:

La criminalización de la colusión evidentemente debilitará este mecanismo, pues difícilmente alguien va a estar dispuesto a denunciarse para eximirse de las multas, pero con el riesgo de ir a prisión. [...] Los incentivos para delatarse igualmente disminuirán, por que quien tiene la intención de denunciarse ignora si será el primero o si otro miembro del cartel ya se delató con anterioridad (Pellegrini, 2015: 4).

Y es que es en relación con la delación compensada donde han surgido algunas de las críticas más interesantes a la idea de criminalizar la colusión que sostienen que:

Justificaciones normativas para la criminalización de la colusión basadas en caracterizaciones y condenas de esta conducta como extremadamente dañina y/o moralmente condenable, son difíciles de conciliar con una política que permite a un delincuente confeso escapar de las sanciones (Beaton-Wells, 2017: 142).

Bajo esta lógica, se señala que habría una incompatibilidad entre comunicar a la sociedad que la colusión es una conducta sumamente grave y dañina, y permitir que en ciertas circunstancias el responsable quede completamente impune por aplicación de la delación compensada, lo que genera «una tensión entre políticas de clemencia y las nociones básicas de justicia de una comunidad, y esa tensión puede llevar a mermar la confianza pública en el sistema» (Beaton-Wells, 2017: 143), ya que «un importante transgresor de reglas queda libre a cambio de proveer información crucial» (Harding, Beaton-Wells y Edwards, 2015: 245).

Esta discusión será abordada con mayor detalle más adelante a propósito de la compatibilidad entre la delación compensada y la criminalización. Por ahora, basta 
señalar que a la hora de dar un fundamento teórico a la idea de criminalizar debe diferenciarse, por un lado, la fundamentación por la vía del reproche jurídico y democrático por el acuerdo colusorio ya cometido y, por otro, la herramienta de la delación compensada. Por tanto, sostener con fines puramente teóricos que nada puede afectar el interés público comprometido en la persecución penal ni el reproche impuesto por medio de la pena, aun cuando de ello se siga una imposibilidad práctica de detectar y sancionar carteles, sería un discurso que caería en el absurdo de no poder luchar contra la colusión. En ese sentido, no parece un mensaje contradictorio señalar a la ciudadanía porque (y no aunque) la colusión es una conducta merecedora de la sanción penal más gravosa que el sistema contempla, se mantiene la vigencia de las herramientas que permiten descubrir esas colusiones, que es el presupuesto básico para poder sancionar.

Por otro lado, la mencionada crítica debe ser entendida en el contexto de las realidades de los autores que emiten dichas críticas. Por ejemplo, en el Reino Unido la percepción ciudadana con respecto a la gravedad de la colusión es opuesta a la percepción chilena. Así, en el Reino Unido hace unos años se tipificó la colusión en circunstancias que «el público en el RU habitualmente no ha desaprobado los carteles» (Jones y Williams, 2014: 110). En otros países, aun cuando se percibe como una conducta reprochable, no se considera como una conducta susceptible de una pena privativa de libertad (Stephan, 2015). Esto llevó a que en algunos países se intentara, al criminalizar, dar un «estigma moral» (Jones y Williams, 2014: 113) a una conducta que no era percibida como tal. La situación en Chile es opuesta, ya que en 2016 un 77\% de los chilenos consideraba que la sanción para la colusión debía incluir penas privativas de libertad (CADEM, 2016: 33). Esto implica que, en el caso chileno, la criminalización tuvo un correlato en las convicciones sociales imperantes (Gagliano y Aracena, 2018: 132) y un rol simbólico criticable, intentando responder a la ciudadanía, pero también buscó adecuar las escalas de castigo a las gravedades de las conductas, siendo el resguardo a la herramienta de la delación compensada una exigencia técnica ineludible.

Todo lo anterior nos muestra que la discusión política de la que tenía que hacerse cargo la nueva normativa era sopesar, por un lado, la necesidad de una reacción estatal acorde a la gravedad de la conducta, influenciado por un fuerte valor simbólico derivado de las inconsistencias del sistema penal chileno y, por el otro, la necesidad de no desvirtuar con ello la delación compensada. Ante ello, el legislador logró llegar a un punto medio en relación con las ideas en pugna, en que sí se establecerían sanciones penales para las personas naturales involucradas en actos colusorios, pero a través de un diseño especial, con elementos que permiten cautelar la delación compensada.

Sin perjuicio de esto último, y de que se trata de un proyecto que oyó las voces de expertos y que logró compatibilizar de buena manera posturas legítimas en pugna, lo 
cierto es que es un proyecto en el que incidió de manera potente el descontento social percibido por los propios parlamentarios, que sintieron que incorporar una sanción penal significativa para delitos de cuello blanco (Sutherland, 1999) era una necesidad social, con lo que el proyecto cumplió también un rol simbólico, queriendo dar una señal de «igualdad» hacia la ciudadanía. Así, durante la tramitación, el senador de Urresti manifestó que el proyecto era necesario, ya que el sistema adolecería de un sesgo de clase (Biblioteca del Congreso Nacional de Chile, 2018: 661). Por su parte, la senadora Lily Pérez sostuvo que era un imperativo moral del congreso, contrastando el castigo de la colusión con la muerte de un vendedor de CD en el incendio de la cárcel de San Miguel (Biblioteca del Congreso Nacional de Chile, 2018: 403). Todo esto ilustra una ya usual utilización del derecho penal como herramienta simbólica, y un intento de legitimación del congreso y del sistema jurídico, «empatando» en punibilidad. A estas alturas, el uso simbólico del derecho penal, por sectores conservadores y progresistas (Larrauri, 2000: 217), es frecuente, aun cuando la particularidad de este caso es que todo esto se compatibilizó con otros argumentos técnicos más coherentes $\mathrm{y}$ atendibles a diferencia de buena parte de las modificaciones penales del último tiempo.

\section{Análisis del tipo penal adoptado}

El debate parlamentario antes descrito llevó a la conclusión de que la inclusión de una sanción penal en el sistema de defensa de la libre competencia era un paso conveniente y necesario. De esta manera, el tipo penal que se incorporó al Decreto Ley 211 quedó redactado en el nuevo artículo 62.

Antes de analizar los elementos del tipo penal, cabe hacer algunos comentarios sobre el inciso final del artículo 62 del Decreto Ley 211, que dispone que:

Será aplicable lo previsto en la Ley 18.216, conforme a las reglas generales. Sin embargo, la ejecución de la respectiva pena sustitutiva quedará en suspenso por un año, tiempo durante el cual el condenado deberá cumplir en forma efectiva la pena privativa de libertad a la que fuere sancionado.

Lo anterior, con la idea de crear una nueva Ley Emilia para casos de colusión (Biblioteca del Congreso Nacional de Chile, 2018: 255). Con respecto a esta deficiente técnica legislativa, se puede sostener que:

- La introducción de cumplimientos efectivos solo viene a intentar dar a la cárcel en cuanto sanción un rol disuasivo que no se ha comprobado, y en cuanto espacio físico, un supuesto rol valorativamente positivo que no tiene: la cárcel no soluciona problemas, sino que los profundiza (Larroulet, 2015). Junto con ello, esta técnica niega el contenido punitivo autónomo de las penas alternati- 
vas a la privación de libertad, lo que constituye un equívoco conceptual serio (Morales y Salinero, 2020).

- En segundo lugar, esta modalidad de cumplimiento objetivo ha sido impugnada en sede de inaplicabilidad ante el Tribunal Constitucional, el que la ha declarado inaplicable en reiteradas ocasiones, sosteniendo que esto afecta el principio de igualdad bajo argumentos preventivos no fundamentados, excediendo la sanción legítima de un hecho punible (STC 2983-16, considerando 32). Este mismo tribunal ha criticado el uso mal argumentado de este tipo de legislaciones (STC 6163-19, considerando 19), que se alza solo como un trato discriminatorio, que atentaría contra el principio de proporcionalidad, contra los límites para el ejercicio del ius puniendi estatal y vulneraría la supuesta finalidad preventivo especial positiva de la pena (STC 6163-19, considerandos 20 y ss.). En ese marco, cabe anticipar que la aplicación de la norma introducida en el inciso final del artículo 62 será objeto de requerimientos de inaplicabilidad ante el Tribunal Constitucional, saturando aún más el sistema de justicia constitucional producto de la insistencia en una deficiente técnica legislativa más bien vinculada al rol simbólico del proyecto.

\section{Contraste entre el tipo penal y el tipo infraccional}

Entre el artículo 3, letra a), y el artículo 62 del Decreto Ley 211, se aprecian ciertas diferencias significativas:

1. La primera diferencia fundamental entre esta disposición y el tipo penal del artículo 62 es que el tipo infraccional se refiere a «acuerdos o prácticas concertadas», mientras que en el tipo penal se mencionan los «acuerdos». Lo anterior no es baladí, sino que se trata de una decisión del legislador (frecuentemente olvidada por el mismo en otros ámbitos) de valerse de la herramienta del derecho penal como ultima ratio, no criminalizando toda conducta, sino solo los llamados «carteles duros» que atentan gravemente contra la libre competencia de los mercados. Esto tiene sentido, ya que es complejo distinguir las prácticas concertadas de simples conductas paralelas del mercado (Gorab y Nehme, 2015: 12), que se consideran lícitas (SCS en causa rol 2578-2012, considerando 79). La segunda razón para sostener la conveniencia de excluir las prácticas concertadas de la sanción penal es que existía un sinsentido en tipificar como ilícito penal las prácticas concertadas, ya que para que proceda la condena en sede penal se debe probar la existencia del delito más allá de toda duda razonable conforme al artículo 340 del Código Procesal Penal, y como expresó el Ministro de Economía en la discusión parlamentaria, las prácticas concertadas «son usualmente acreditados a través de indicios y prueba económica» (Biblioteca del Congreso Nacional de Chile, 2018: 186), siendo complejo superar dicho estándar, por lo que se prefirió excluirlas del tipo previendo ese resultado. 
Lo anterior implica que, bajo esta regulación, se pueden presentar situaciones que si bien son susceptibles de ser sancionadas en sede infraccional, no serían acciones típicas en los términos del artículo 62 del Decreto Ley 211, ya que el tipo penal contenido en dicha norma solo sanciona los carteles duros, con acuerdo expreso.

Ante la posibilidad de que se den casos de prácticas concertadas que sean, por tanto, sancionables al alero del artículo 3, letra a), del Decreto Ley 211, más no sancionables en sede penal, resulta útil esclarecer qué significa acuerdo y qué significa el concepto de práctica concertada.

El concepto de acuerdo lo debemos entender como la fiel expresión de la voluntad entre los competidores involucrados, que tiene como sustento una voluntad expresa y consciente de actuación. Así ha sido definido por el Tribunal General de la Unión Europea, que sostuvo que el concepto de acuerdo «se basa en la existencia de una concordancia de voluntades entre por lo menos dos partes, cuya manifestación carece de importancia siempre y cuando constituya la fiel expresión de tales voluntades» (Sentencia del Tribunal General de la Unión Europea, T-41/96: 200o, párrafo 69), entendiéndolo en un sentido amplio. Esto último ha sido reafirmado en nuestro país por el TDLC y la Corte Suprema. Así, el TDLC sostuvo que «acuerdo» incluye:

Múltiples formas contractuales, convenciones, meras tratativas, promesas, protocolos de entendimiento, «acuerdos o pactos de caballeros», pautas de conducta, circulares, entre otros. Es posible que tal acuerdo sea verbal, se manifieste en uno o más instrumentos o incluso en una seguidilla de meros actos materiales (Sentencia del TDLC 145/2015, considerando 5).

En el mismo sentido, la Corte Suprema ha sostenido que un acuerdo «puede ser expreso o tácito, escrito u oral, de ejecución instantánea o diferida, formal o informal. Además, puede ser implícito e incluso tácito, solamente exige que se manifieste voluntad de los partícipes en orden a concretarlo» (SCS en causa rol 2578-2012, considerando 78 ).

En cuanto a las prácticas concertadas, estas han sido definidas como «una forma de coordinación entre empresas que, sin haber desembocado en la celebración de un convenio propiamente dicho, sustituye conscientemente los riesgos de la competencia por una cooperación práctica entre ellas» (Sentencia del Tribunal de Justicia de la Unión Europea, C-286/13, p. 121; citado en Araya, 2015: 245).

De una manera más clara, el mismo Tribunal sostuvo en el caso Suiker Unie con Comisión:

Cualquier toma de contacto directa o indirecta entre dichos operadores que tenga por objeto o efecto bien influir en el comportamiento de mercado de un competidor actual o potencial, o bien desvelar a dicho competidor el comportamiento que uno mismo ha decidido o tiene intención de mantener en el mercado (Sentencia del Tribunal de Justicia de la Unión Europea, C-40-73, párrafo 174). 
Es decir, las prácticas concertadas implican un consenso entre competidores por medio del cual dejan de actuar conforme al deber de independencia impuesto por el ordenamiento jurídico de libre competencia, sustituyendo lo anterior por una coordinación práctica que no se lleva a cabo por medio de acuerdos.

Para que se pueda acreditar la existencia de una práctica concertada, la doctrina ha sostenido que se deben reunir tres elementos copulativos (Grunberg, 2017: 22-25):

- Contacto entre empresas para «eliminar de antemano la incertidumbre referente al comportamiento futuro de sus competidores» (Sentencia del Tribunal de Justicia de la Unión Europea, C-40-73, párrafo 175) siempre que la información intercambiada sea estratégica.

- Consenso en torno a cooperar en lugar de competir: un encuentro de mentes entre los competidores.

- Conducta en el mercado basada en la concertación entre las partes: Es decir, los dos elementos antes mencionados deben traducirse en una conducta externa por parte de las empresas incumbentes en el mercado, existiendo causalidad entre ambos.

- Junto con esa conceptualización y caracterización de las prácticas concertadas, se han señalado ciertas situaciones específicas en que entenderíamos que estamos frente a prácticas concertadas, como las tomas de contacto con competidores para reducir o eliminar la incertidumbre, los intercambios de información comercialmente sensible, entre otras (Araya, 2015: 245).

La exclusión de las prácticas concertadas del ámbito penal ha sido discutida a nivel comparado. Así, hace pocos años en Australia, la Australian Competition and Consumer Comission (ACCC) propuso «extender la legislación anticartel a conductas que no llegan a ser un acuerdo» (Harding, Beaton-Wells y Edwards, 2015: 244), generando una inmediata respuesta doctrinal de rechazo a esa propuesta por considerar que ello llevaba a una indeterminación de las conductas punibles y a la inclusión de sanciones penales en ilícitos cuya magnitud solo debía ser sancionable como infracción a la libre competencia (Beaton-Wells y Fisse, 2010) bajo criterios de proporcionalidad.

Así, ante la posibilidad de que en el fututo se verifiquen casos cuyos hechos sean calificables como prácticas concertadas por el TDLC (y/o la CS), estas serán perfectamente sancionables en sede infraccional. Será imposible su persecución penal por no ser típicas en los términos del artículo 62.

Lo anterior nos indica que el tipo penal sanciona solo los acuerdos expresos, excluyendo no solo las prácticas concertadas, sino también los llamados acuerdos tácitos, lo que responde a la noción jurisprudencial y doctrinariamente avalada de que «acuerdo tácito»y «práctica concertada» serían sinónimos (Gunberg, 2017: 17), lo 
que fue refrendado durante la tramitación (Biblioteca del Congreso Nacional de Chile, 2018: 113 y 6o). Esta idea de sancionar solo a los carteles duros se condice con la regulación comparada, como la contenida en el artículo 254 del Código Penal Federal Mexicano o la sección 188 del Enterprise Act de 2002 en el Reino Unido.

Con todo esto, el legislador buscó dar certeza con respecto a los límites de la sanción penal y, con ello, volver previsible los resultados de la delación compensada para el potencial delator, reafirmando el carácter de ultima ratio del derecho penal, y dando certeza sobre los límites de la sanción penal, lo que es de suma relevancia (Harding, Beaton-Wells y Edwards, 2015: 244) porque una tipificación clara y específica es un prerrequisito para el adecuado funcionamiento de la delación compensada (Harding, Beaton-Wells y Edwards, 2015: 244).

2. La segunda diferencia entre el artículo 3, letra a), del Decreto Ley 211, y el nuevo artículo 62, se refiere a las hipótesis de carteles duros que se sancionan en uno y otro caso en relación con las licitaciones. Mientras el artículo 3, letra a), sanciona los acuerdos o prácticas concertadas que recaen en licitaciones, en términos generales, el artículo 62 solo sanciona penalmente los acuerdos que recaen sobre licitaciones realizadas por empresas públicas, privadas prestadoras de servicios públicos o por órganos públicos con lo que la aplicación de este último precepto es más restringida.

\section{Incorporación de una regla per se}

Una de las grandes modificaciones que efectuó la nueva ley en el artículo 62 es que, en principio, se incorpora una regla per se para la sanción penal de los acuerdos colusorios en términos de la introducción de un delito de peligro abstracto. Es decir, los acuerdos:

Son considerados como anticompetitivos por la sola existencia del acuerdo o práctica concertada que recaiga sobre alguna de las variables de competencia esenciales descritas por la norma, sin que sea necesario acreditar la existencia de poder de mercado (Grunberg, 2017:17).

En otras palabras, la regla per se implica en general que «el acuerdo será condenado sin prueba de que los acusados hayan afectado o tengan el poder de afectar el precio» (Areeda, 1981: 19). Por tanto, en términos jurídico-penales lo que el legislador hizo por medio de la incorporación de una regla per se, como sostuvo el profesor Mañalich, fue plasmar «la tipificación de un delito de peligro abstracto para la libre competencia como bien jurídico colectivo» (Biblioteca del Congreso Nacional de Chile, 2018: 363), lo que fue reiterado por el entonces fiscal nacional económico como una inquietud asociada al proyecto (Biblioteca del Congreso Nacional de Chile, 2018: 354).

Esta decisión no fue poco controvertida, ya que ciertos sectores políticos abogaron, durante la tramitación parlamentaria, porque se estableciera el requisito de exigencia 
de poder de mercado a nivel típico (Biblioteca del Congreso Nacional de Chile, 2018: 168), lo que también ha sido refrendado por parte de la doctrina como un requisito de idoneidad para poner en peligro el bien jurídico tutelado.(Artaza, 2017: 360)

Esta lógica se fundamentó en una apreciación empírica común en sede de libre competencia: «la experiencia, [...] de que un cartel de fijación de precios es socialmente ineficiente en la inmensa mayoría de los casos (por no decir, derechamente, siempre)» (Grunberg y Montt, 2017: 322-323). Aun cuando dicha constatación es cierta y plenamente aplicable en sede infraccional, esto no quiere decir necesariamente que la herramienta penal es la idónea para perseguir todas esas conductas socialmente ineficientes. Así, el legislador priorizó una sanción penal de todo cartel independiente de su potencial afectación a la libre competencia, lo que puede discutirse como decisión desde el punto de vista de la lesividad.

En términos generales, las infracciones a la libre competencia deben medirse y sancionarse en base a la «regla de la razón» conforme a la cual se examinan los factores particulares del caso, analizando la participación de mercado, valorando las eficiencias versus los efectos anticompetitivos, (Valdés, 2008: 107-108). con lo que no hay sanción cuando la conducta es explicable desde la perspectiva de bienestar. (Grunberg y Montt, 2017: 319)

Excepcionalmente, se elaboró el sistema de la regla per se más eficiente y directo aplicable para «aquellas prácticas de negocios que se sabe a ciencia cierta que son manifiestamente anticompetitivas» (Grunberg y Montt, 2017: 320). La regla per se implica que el tribunal no deberá las defensas de eficiencia, sino que:

Tratándose de conductas que a priori se sabe son manifiestamente anticompetitivas como lo es la colusión, «el mal supremo de la libre competencia», los tribunales están autorizados a condenar a quienes incurran en las mismas sin necesidad de que el demandante realice un completo análisis de mercado relevante y efecto anticompetitivo, y restringiendo la facultad del demandado de invocar defensas de eficiencia (Grunberg y Montt, 2017: 320).

Su justificación como técnica legislativa es, como ha sido mencionado, empírica, ya que se ha probado por la experiencia que existe un bajo o nulo riesgo de lograr falsos positivos, y que en la generalidad de los casos son conductas ineficientes. En segundo lugar, tendría un fundamento en la certeza jurídica, ya que «entrega una clara señal a los actores económicos sobre qué conductas no pueden realizar» (Grunberg y Montt, 2017: 322), descartando toda duda o interpretación basada en criterios de eficiencia. Sin perjuicio de la validez de esos criterios en sede infraccional, es cuestionable la introducción en la legislación penal como un delito de peligro abstracto, ya que impide una adecuada limitación del poder punitivo estatal y una clara delimitación de las conductas dañinas para el bien jurídico tutelado, lo que más bien queda entregado a la FNE. 
Por tanto, con la Ley 20.945 se incorpora una especie de regla per se en el artículo 62 a propósito de la sanción penal bajo la figura de un delito de peligro abstracto, lo que implica que para tener por consumado el delito no se requiere la acreditación de un poder de mercado conferido por el acuerdo, sino que basta la celebración de este para que se satisfaga la tipicidad objetiva de la conducta en ese punto.

Así, no hay duda de que se deben acreditar los restantes elementos de configuración del ilícito penal (Gagliano y Aracena, 2018: 146), en particular que el acuerdo existe, lo que implica comprobar la concordancia de voluntades en cuanto conjunto de actos positivos tendientes a consolidar un acuerdo. En cuanto a la tipicidad subjetiva, se debe probar el dolo en la ejecución de dichas acciones impidiéndose la imputación a título culposo (Gagliano y Aracena, 2018: 140), satisfaciéndose dicha tipicidad subjetiva tanto con dolo directo como eventual. (Gagliano y Aracena, 2018: 140).

En este marco, es de esperar que durante los primeros casos que se ventilen en tribunales penales se discuta si debe existir algún tipo de idoneidad de la conducta para poner en peligro la libre competencia en resguardo del principio de lesividad (Artaza, 2017: 360). Más allá de esa legítima discusión, parece cuestionable la introducción de este tipo de delitos, ya que abre de manera excesiva el campo de aplicación del tipo e implica que la lesividad se custodia solo con el criterio de la FNE, lo que no parece otorgar garantías suficientes de limitación del ejercicio del poder punitivo, siendo en general el uso de un delito de peligro abstracto una técnica legislativa cuestionable en ese aspecto (Politoff, Matus y Ramírez, 2003: 69).

\section{Ausencia de requisitos subjetivos adicionales en la configuración típica}

Por otro lado, dentro de este mismo análisis de los requisitos de configuración del tipo penal, el legislador chileno optó por no incluir expresamente en el tipo requisitos subjetivos adicionales para dicha configuración, lo que es un acierto a la luz de la experiencia comparada. El mejor ejemplo de esto es el Reino Unido, donde se incluyó en el tipo penal un requisito de que la conducta se ejecute con «deshonestidad» para evitar sancionar penalmente conductas no sancionables en sede infraccional (Jones y Williams, 2014: 106), lo que se explicaría en un sistema sin secuencialidad jurisdiccional en que la vía penal y la infraccional corren por caminos separados pero paralelos, por lo que este requisito subjetivo venía a actuar como límite a la sanción penal.

Como es evidente, la prueba de la deshonestidad es prácticamente imposible y eso ha llevado a que, en el Reino Unido, «en vez de la predicción de las 6 a 10 persecuciones por año, en 10 años solo 3 personas, en relación con un solo cartel -Marine Horses-, han sido condenadas a prisión» (Jones y Williams: 2014: 107), mermando toda efectividad de la persecución penal. 


\section{Diseño institucional adoptado por la Ley 20.945}

Como fue esbozado, la manera en que el legislador decidió regular las relaciones entre la persecución especializada en sede infraccional y la persecución penal fue especial y difiere de la regla general en nuestro sistema. En ese sentido, todas las particularidades de este tipo de criminalidad establecen un conjunto de requisitos para una política criminal efectiva contra los carteles, los que deben ser cautelados por el legislador y por los operadores del sistema de justicia penal y de libre competencia. Esto es especialmente relevante en los tiempos actuales, en que los elementos de este diseño institucional están siendo objeto de ataque bajo consignas generales con tintes demagogos.

En términos globales, el diseño institucional ideado por el legislador chileno se articula de la siguiente manera: primero, para que proceda el ejercicio de la acción penal debe existir una sentencia condenatoria firme en sede infraccional. Luego, quedaba en manos del fiscal nacional económico la decisión de interponer o no la querella que dé inicio a la persecución en sede penal, estableciendo el artículo 64, inciso 2, que el Fiscal Nacional Económico debe hacerlo «en aquellos casos en que se tratare de hechos que comprometieren gravemente la libre competencia de los mercados».

\section{Secuencialidad jurisdiccional}

Como se mencionó, se optó por exigir una sentencia condenatoria firme en sede infraccional como requisito previo para la procedencia de la investigación penal, lo que fue largamente debatido.

En un comienzo, el Ministerio Público abogaba por la existencia de procesos paralelos, es decir, que pudiera investigar mientras se lleva a cabo el proceso en sede de libre competencia. Durante la tramitación parlamentaria, Andrés Montes, actuando como fiscal nacional, sostuvo lo anterior argumentando que «para la persecución penal es muy relevante el tiempo transcurrido entre el momento en que los hechos típicos tiene lugar, y cuando se inicia la investigación criminal», (Biblioteca del Congreso Nacional de Chile, 2018: 629) señalando que se perdía tiempo fundamental para la investigación penal mientras se ventilaba el asunto en sede de libre competencia, lo que fue secundado en algún momento de la discusión por algunos parlamentarios como el senador Araya, quien incluso abogó por que el fiscal nacional económico pudiese interponer la acción penal en cualquier momento de la investigación (Biblioteca del Congreso Nacional de Chile, 2018: 636).

La FNE se opuso a lo anterior argumentando que sería contraproducente la existencia de dos procesos paralelos, y que el carácter de la investigación de la FNE exigía que esta fuera llevada de manera exclusiva por esta agencia especializada. La razón de fondo de la FNE estaba íntimamente relacionada con los elementos propios de la 
delación compensada, que exigen un proceso confidencial, previsible, cierto y sumamente cauteloso en el manejo de la información, que se vería interferido por el legítimo afán investigativo del Ministerio Público. Además, se argumentó que no existirían incentivos para entregar información en el proceso de delación compensada si es que en paralelo se efectuaba una investigación penal por esos mismos hechos, lo que desvirtuaría los elementos propios de esta herramienta.

El requisito de la secuencialidad se vuelve fundamental a la hora de diseñar un adecuado sistema institucional, ya que permite que el proceso infraccional se lleve a cabo sin interferencias por parte del ente persecutor que impidan que la delación compensada cumpla su función en la detección de carteles y de recopilación de antecedentes, lo que posibilita la posterior prueba y sanción.

La racionalidad de establecer este filtro al avanzar la discusión fue un hecho asumido como lógico incluso por el propio fiscal nacional (Biblioteca del Congreso Nacional de Chile, 2018: 649).

Para esto, fue clave el rol que jugó la historia pasada, específicamente el caso de la colusión de las empresas productoras de papel tissue en que se evidenció la colisión entre los distintos principios y objetivos tanto del proceso penal como del proceso infraccional (STC 2934/2015, considerandos 3 y 5), y la necesidad de establecer una secuencialidad entre uno y otro, con el objetivo de que el legítimo y necesario afán investigativo del Ministerio Público no implicase una merma de la efectividad de la delación compensada al afectar las condiciones de confidencialidad y previsibilidad con las que dicha herramienta funciona (Beaton-Wells, 2017: 128).

Junto con el problema, en un sentido más global, otro dilema de los procesos paralelos sería que:

Haría esperable que se invoquen ante el TDLC garantías propias de lo penal como el derecho a no autoincriminación, a guardar silencio, exigencias de estándar de prueba más altas y otros, que entorpecerían la labor del tribunal especializado [...]. Se generaría, así, el riesgo de una neutralización procesal de la capacidad de apreciación de la prueba que ha mostrado el TDLC (Gorab y Nehme, 2015: 12).

Este riesgo es a todas luces cierto, y así lo demuestra la práctica judicial en nuestro país antes de la reforma, en que:

Diversas acciones de inaplicabilidad por inconstitucionalidad han sido interpuestas ya con motivo de procedimientos sustanciados en el TDLC, alegando el incumplimiento de garantías penales: caso pollos (TC rol 2381-12); farmacias (TC rol 1406o9); y buses interurbanos I (TC rol 2658-14). Aunque todas ellas, sin éxito» (Gorab y Nehme, 2015: 12).

Aun cuando el establecimiento de la secuencialidad jurisdiccional es una medida necesaria en el afán de evitar un entorpecimiento entre las labores de uno y otro 
proceso (Biblioteca del Congreso Nacional de Chile, 2018: 837), por sí mismo no es suficiente para evitar el uso de garantías procesales penales en sede infraccional. Esto porque garantías procesales penales, como el derecho a no autoincriminarse (ya sea como testigo, en las hipótesis del artículo 305 del Código Procesal Penal, o como posible futuro imputado, en el ejercicio del derecho a guardar silencio del artículo 93, letra g), del mismo código) van a ser usadas en sede infraccional, en la absolución de posiciones o al declarar como testigo, ante la eventual persecución penal que surja como consecuencia de la decisión del TDLC en el proceso en el cual están declarando.

La racionalidad de la secuencialidad jurisdiccional radica, más bien, en impedir el entorpecimiento paralelo de procesos con fines, procedimientos y principios diferentes, y liderados por instituciones distintas, permitiendo el adecuado desarrollo de uno y otro, y estableciendo un filtro a la persecución penal, que solo procederá en casos en que el TDLC acredite que ha existido una vulneración a la libre competencia.

En la Guía interna para la interposición de querellas por el delito de colusión de la FNE, elaborada en junio de 2018, que explicita los criterios que este organismo tendrá en consideración a la hora de analizar la procedencia de la interposición de la querella, se establece que el primer paso es examinar «si existe concordancia entre aquellos hechos cuya existencia queda establecida en la sentencia definitiva dictada en el juicio contravencional y la descripción legal prevista en el artículo 62» (FNE, 2018: 5).

Esto ilustra que la secuencialidad jurisdiccional, como requisito de procedencia de la persecución penal, no solo requiere que exista una sentencia condenatoria, sino que, a juicio de la FNE, el mandato legal es analizar si es que los presupuestos de la sentencia condenatoria son suficientes como para enmarcarse dentro del presupuesto típico del artículo 62, debiendo efectuar dicho análisis siempre que la sentencia firme y ejecutoriada sea condenatoria, incluyendo, lógicamente, aquellos casos en que el TDLC rechace el requerimiento, pero luego de un recurso de reclamación, la Corte Suprema lo acoja (FNE, 2018: 6).

\section{Ejercicio de la acción penal}

El segundo filtro establecido por el legislador, y el más polémico, se refiere a la decisión de dejar exclusivamente en manos del fiscal nacional económico la decisión de interponer o no la acción penal una vez que la sentencia dictada en sede infraccional se encuentre firme y ejecutoriada.

Este asunto fue intensamente discutido, ya que se barajaron tres opciones: que solo quedara radicado en el Ministerio Público, que quedara radicado exclusivamente en la FNE o que la acción pudiera ser ejercida por cualquiera de las dos instituciones indistintamente. Este punto nunca generó consenso entre ambas instituciones (Biblioteca del Congreso Nacional de Chile, 2018: 649). 
A modo de aclaración previa, es fundamental entender que dentro del artículo 83 de la Constitución de la República de Chile es perfectamente posible que se otorgue el ejercicio de la acción penal a una institución distinta al Ministerio Público, siempre y cuando la investigación penal quede radicada exclusivamente en manos del Ministerio Público (STC 1341-09; STC 1349-09; STC 1380-09; STC 2680-14; STC 2702-14).

Durante la discusión sobre el ejercicio de la acción penal, el interés del Ministerio Público era que el ejercicio de la acción penal quedara radicado exclusivamente en dicho organismo (Biblioteca del Congreso Nacional de Chile, 2018: 649) en su calidad de representante del interés de la sociedad, argumentando que toda otra decisión implicaría un quiebre al principio de igualdad. El interés de la FNE, por otro lado, era que la acción penal quedara radicada en sus manos por el resguardo de la delación compensada y por consideraciones de política criminal: que solo los casos más graves llegaran a sede penal, por ser el derecho penal ultima ratio, y por carecer de sentido sancionar ciertos acuerdos que, aun sancionables en sede infraccional, no dan pie para una imputación penal, cuya existencia se debe determinar caso a caso.

La decisión de radicar esta decisión en el ente especializado ha sido reconocida también en la doctrina comparada, argumentando que la idoneidad de la agencia especializada en materia de libre competencia radica en que esta cuenta con «un extensivo conocimiento y experiencia en economía, en la forma general en que operan y en la estructura que tienen los carteles y en las normas aplicables a los carteles» (Whelan, 2016: 255).

La relevancia de esto en términos de técnica legislativa es que este diseño es un medio para evitar que se den problemas como el que se suscitó en la legislación del Reino Unido, donde una de las mayores críticas al diseño institucional adoptado es que «no se dibujó ninguna línea entre la conducta colusoria merecedora de sanción penal, y la conducta no merecedora de esta» (Jones y Williams, 2014: 118), lo que solucionaría en la legislación chilena sin acudir a requisitos típicos subjetivos, sino que dejando en manos del fiscal nacional económico el establecimiento de esa línea divisoria, la que, para propender a una mayor transparencia y efectividad, idealmente deberá constar en un acuerdo conjunto entre la FNE y el Ministerio Público en que se acuerden estos criterios. ${ }^{4}$

Este doble filtro institucional es un diseño relativamente innovador desde la mirada del derecho comparado. En general, en otras latitudes se ha radicado la persecución penal en una agencia especializada (por ejemplo, la Australian Competition and Consumer Commission - ACCC- en el caso australiano y la Competition and Markets authority —CMA— en el Reino Unido), que lleva la persecución penal en

4. Para un adecuado ejemplo de cómo efectuar esos acuerdos, véase el Memorandum Of Understanding australiano, firmado el 15 de agosto de 2014 entre la ACCC y la CDPP, o el convenio celebrado en Canadá entre la Canadian Competition Bureau y la DPP. 
el ámbito judicial, corriendo en paralelo el proceso tendiente a atribuir responsabilidad infraccional. La complicación de lo anterior era una notable interferencia en el ejercicio de la investigación, que produce conflictos prácticos en la consecución de pruebas y una tensión institucional entre las agencias persecutoras, como ocurrió en Chile cuando se intentó llevar a cabo procesos paralelos en sede penal y en sede infraccional. El caso del Reino Unido, desde 2003 a 2013, es ilustrativo de dicha interferencia, y fue criticado desde sus comienzos por la doctrina (Joshua, 2004: 3).

El diseño chileno, en materia de ejercicio de la acción penal para el nuevo delito de colusión, más bien decidió seguir el ejemplo australiano (con la gran diferencia de lo que vimos en el subcapítulo anterior referido a la secuencialidad jurisdiccional). En Australia, la Competition and Consumer Act, Part IV, Division 1, sanciona los acuerdos colusorios tanto desde el punto de vista infraccional como el penal. En este diseño, la ACCC actúa de manera coordinada con el Commonweath Director of Public Prosecutions (CDPP) equivalente al Ministerio Público.

En el sistema australiano, la ACCC es el organismo especializado que tiene la potestad de investigar los hechos constitutivos de colusión y de tramitar las postulaciones a las políticas de clemencia. Luego de esto, cuando lo estima procedente, la ACCC presenta la denuncia correspondiente a la CDPP, quien investiga los hechos, lo que constituye una diferencia con el sistema chileno en que la FNE interpone directamente la querella ante el tribunal correspondiente. En el caso chileno, cabe consignar, se estableció el rol de la FNE de querellarse, y no solo de denunciar, ya que el objetivo fue que la FNE adoptara un rol activo en la investigación y luego en el proceso penal, debiendo coadyuvar en la carga probatoria y dar curso progresivo al proceso, ya que es este organismo el que contará con toda la evidencia para lograr una condena (Biblioteca del Congreso Nacional de Chile, 2018: 233).

Junto con este diseño institucional, hay un segundo elemento a ser destacado en la experiencia australiana en la materia: la existencia de un Memorandum Of Understanding de 2014 entre la ACCC y la CDPP, que constituye un acuerdo entre ambas instituciones sobre los criterios bajo los cuales se entenderá que un acuerdo colusorio es susceptible o merecedor de sanción penal, y que además busca generar tanto criterios como estándares procedimentales y operativos entre ambas agencias, procurando evitar roces institucionales.

Esto último es algo interesante que debe ser implementado en Chile, ya que sería un claro paso hacia adelante que la FNE y el Ministerio Público suscribiesen un convenio de coordinación en que se especificaran los criterios de actuación de ambas agencias, en el que se explicitara cuándo será conveniente y pertinente ejercer la acción penal - bajo qué criterios técnicos se determinará o cuando una conducta afectará gravemente la libre competencia en los mercados-, y en el que se establezcan los mecanismos de coordinación y traspaso de información entre ambas agencias. Esto morigeraría la ya sostenida crítica efectuada por el Ministerio Público a esta 
regulación, ya que el Ministerio Público, como representante del interés social en la persecución de delitos, colaboraría activamente con la determinación de criterios político-criminales de persecución de carteles. Lo anterior ya ha sido recomendado por parte de la doctrina nacional (Gorab y Nehme, 2015: 13).

\section{Parámetros para el ejercicio de la acción penal}

La Guía interna para la interposición de querellas por el delito de colusión, elaborada por la FNE, establece los pasos y criterios que tendrá en consideración la FNE al momento de decidir la interposición de la querella. Esta guía establece un proceso de tres etapas a manos de la División de Litigios de la FNE, que luego es informado al Fiscal Nacional Económico para que este decida (FNE, 2018: 10). Las etapas sucesivas son:

- Examinar la concordancia entre los criterios establecidos en la sentencia del TDLC o de la Corte Suprema y la descripción legal del artículo 62.

- Evaluar si los hechos establecidos por el TDLC comprometen o no gravemente la libre competencia en los mercados para analizar si la interposición de la querella le es facultativa o no en términos del artículo 64, incisos 1 y 3.

- Si la interposición le es facultativa por no ser una conducta que comprometa gravemente la libre competencia en los mercados, la FNE analizará si ejerce o no su facultad de querellarse.

El artículo 64 inciso 2: Conducta que comprometa gravemente la libre competencia en los mercados

El inciso segundo del artículo 64 establece que el fiscal nacional económico tendrá el deber de interponer la acción penal cuando la colusión establecida por sentencia ejecutoriada afecte gravemente la libre competencia en los mercados, lo que ha sido entendido por algunos como una condición objetiva de punibilidad (Gagliano y Aracena, 2018: 145).

La exigencia de este inciso segundo se debe tanto a un interés por solo perseguir a los carteles duros como a un afán de resguardar el interés social que hay tras la persecución de estos delitos. El interés técnico general del ejecutivo al exigir esto pareciera ser radicar en este punto la valoración sobre la lesividad de la conducta, y así filtrar la aplicación de la herramienta penal, como se sostuvo durante la tramitación parlamentaria (Biblioteca del Congreso Nacional de Chile, 2018: 677).

En el ámbito comparado, el mencionado convenio celebrado en Australia entre la ACCC y la CDPP establece los siguientes criterios para determinar cuando estamos ante un «cartel serio»: 
Uno o más de los siguientes factores: 1) que se trate de una acción oculta; 2) si tuvo lugar o hubo un potencial importante de que la conducta investigada produjera un daño económico serio; 3) si ella tuvo una larga vigencia en el mercado respectivo; 4) si causó un impacto significativo en el mercado en el cual tuvo lugar; 5) si implicó un detrimento económico significativo para la ciudadanía o un conjunto relevante de la misma; 6) la reincidencia; 7) el hecho de que estén involucrados directivos que negociaron y materializaron activamente el acuerdo; y 8) que el gobierno haya sido víctima (Biblioteca del Congreso Nacional de Chile, 2018: 676 y 677).

Junto con esto, también se ofreció el ejemplo del Reino Unido, en que la denominada Oficina de Fraudes Serios también estableció un conjunto de criterios para establecer en qué casos procedía la acción penal, los que también se encuentran explicitados como criterios ejemplificadores en la historia de la ley. Así, esta agencia determinó:

1) La cantidad de personas involucradas; 2) los montos comprometidos en la operación colusiva; 3) la duración del cartel; 4) el nivel de culpabilidad que exhiben los imputados, en el sentido de si estaban en condiciones de entender el alcance anticompetitivo de su conducta, la gravedad de la misma y el interés público que presumiblemente afectarían; 5) el impacto que ha tenido el cartel en la comunidad; y 6) si la persecución penal representa una respuesta proporcionada al problema, considerando el probable resultado de la misma, tanto desde el punto de vista la retribución como de la prevención general (Biblioteca del Congreso Nacional de Chile, 2018: 677).

Por otro lado, dichos criterios también pueden recogerse al momento de fallar el TDLC condenando a los competidores involucrados, ya que dicho fallo establecerá la multa en base a criterios de gravedad, por lo que, de establecerse una sentencia condenatoria, se explicitarán también criterios de gravedad, como lo explicó el Ministro de Economía durante la tramitación (Biblioteca del Congreso Nacional de Chile, 2018: 869).

Estos criterios de determinación de gravedad, a los que el entonces ministro hacía alusión, son:

La duración de la colusión, el porcentaje de participación de mercado que sumen en conjunto las empresas coludidas, el nivel de afectación masiva a la población, según la demanda del bien o servicio o, en otras palabras, el hecho de tratarse de bienes de primera necesidad para la ciudadanía. También deberá considerar el ámbito geográfico afectado, la baja o nula sustitución del bien o servicio, la magnitud del alza de precios del bien o servicio, la vulnerabilidad de ciertos grupos de consumidores afectados y si el acuerdo fue promovido, mantenido y monitoreado en el seno de una asociación gremial (Biblioteca del Congreso Nacional de Chile, 2018: 869). 
Lo que el inciso 2 quiere dejar en claro, por tanto, es que será el criterio técnico especializado de la FNE el que decidirá qué casos son susceptibles de persecución penal, definiendo dicho organismo la política criminal en este ámbito, pero teniendo el deber de interponer la acción penal en los casos que comprometan gravemente la libre competencia, lo que implica que, para que se aplique el deber del inciso 2, se exige un nivel de gravedad que es superior a la gravedad propia de toda conducta colusoria sancionada en sede infraccional, ya que siempre la sentencia del TDLC tendrá consideraciones de gravedad de la conducta para fundar su condena, debiendo el análisis en este punto ser más complejo y acabado, pues lo contrario equivaldría a sostener que la sola condena en sede infraccional configuraría el requisito de comprometer gravemente la libre competencia, lo que es ajeno al sentido de la reforma.

Por otro lado, la Guía interna para la interposición de querellas por el delito de colusión de la FNE establece de manera concreta los criterios bajo los cuales la FNE entiende que tiene este deber de interponer la querella. Además, establece los criterios bajo los cuales se tomará esta decisión por parte de la FNE (FNE, 2018: 8 y ss.):

Criterios relativos al hecho punible:

- Que se trate de un acuerdo contrario al artículo 3, letra a), del Decreto Ley 211, y si la existencia del acuerdo ha sido dada a conocer al público o tiene un carácter secreto.

- Magnitud de los efectos que produjo o fue apto para producir, especialmente si afectó o fue apto para afectar de manera masiva a la población, si el hecho confirió o fue apto para conferir a los infractores poder de mercado en el mercado relevante afectado, y si el hecho afectó o fue apto para afectar todo el territorio nacional.

- Magnitud de los beneficios económicos.

- Extensión temporal del acuerdo: al respecto señala que siempre será significativo cuando se extienda por tres años o más.

- Naturaleza del mercado: Puede tomar en consideración el objeto de el o los acuerdos, analizando si se trata de bienes o servicios de primera necesidad, de consumo masivo, o de baja o nula sustituibilidad.

- Intervención de una asociación: la FNE analiza si el acuerdo fue organizado, coordinado, celebrado, ejecutado o monitoreado con la participación de una asociación o entidad que reúne a competidores. 
Criterios relativos al comportamiento de las personas penalmente responsables por el hecho

Toma en consideración la gravedad manifiesta de las intervenciones individuales, los roles claves desempeñados, si ya habían tenido intervención en otras infracciones del artículo 3 y, en general, los antecedentes que justifiquen la necesidad de solicitar la aplicación de la pena de inhabilitación prevista por ley.

\section{Criterios relativos a la probabilidad de éxito de la acción} penal y los objetivos de la libre competencia

Es un factor que puede generar más controversia, ya que está sujeto a un análisis más valorativo y predictivo que los demás por parte de la FNE. La Guía, en este sentido, señala que la decisión:

Debe orientarse a sus fines institucionales de protección de la libre competencia en términos de sancionar y disuadir conductas que contravienen la libertad de los agentes en el mercado y perjudican a los consumidores y a la economía en su conjunto.

Luego la FNE especifica lo anterior, señalando que este criterio se verá satisfecho cuando la medida sea necesaria, proporcional y compatible con el cumplimiento de los objetivos del Decreto Ley 211. Junto con ello, el segundo análisis que la FNE debe efectuar en este punto se refiere a una proyección sobre el posible éxito de la acción penal (que tenga «una probabilidad apreciable de prosperar»), ya que, a juicio de la FNE, solo así se cumple con la finalidad disuasoria de la criminalización. Es previsible que este análisis sea el más controvertido, lo que exige por parte del ente especializado una fundamentación acabada en caso de que entienda que este no se satisface.

Como fue mencionado, en casos en que no se configure este requisito para que surja el deber de interponer la querella, la FNE tendrá la facultad de interponerla bajo sus propios criterios técnicos y especializados, lo que se desprende del inciso 3 del artículo 64. En los casos en que no comprometa gravemente la libre competencia en los mercados, el fiscal nacional económico puede no interponer la acción penal, pero debe emitir una decisión fundada al respecto señalando las razones que lo llevan a tomar esa decisión. Esto constituye otro mecanismo tendiente a reducir el ámbito de discrecionalidad al momento de interponer la querella correspondiente en casos que sean susceptibles de persecución penal, pero junto con esto, darle viabilidad legal a que, en base a criterios técnicos fundados, la FNE decida no perseguir penalmente un acuerdo colusorio, aun cuando se cumplan los requisitos para que proceda la persecución penal, afirmando el carácter de ultima ratio de este (Biblioteca del Congreso Nacional de Chile, 2018: 844). 
Por último, complementando lo anterior, la ley le otorga un plazo a la FNE para tomar la decisión antes mencionada, señalando el inciso 4 del artículo 64 que esta debe tomarse en seis meses desde que se encuentre ejecutoriada la sentencia definitiva del TDLC. Estos seis meses no corresponden a la prescripción de la acción penal, contenida en el artículo 65 del Decreto Ley 211 (10 años desde que quede ejecutoriada la sentencia del TDLC), sino que es un término establecido por el legislador para que el fiscal nacional económico decida, en base a sus criterios técnicos y con el abanico de posibilidades antes mencionadas, si corresponde interponer o no la acción penal en esos casos, por lo que, transcurridos los seis meses y a la luz de nuevos antecedentes, la FNE puede interponer la querella respectiva. Por obvio que pueda parecer esto, generó cierta controversia durante la discusión parlamentaria. Así, el senador Navarro en la discusión en sala sostuvo lo siguiente: «si se dicta la sentencia y en el mes séptimo se descubren nuevos antecedentes, ¿me van a decir que la posibilidad de querellarse está prescrita?» (Biblioteca del Congreso Nacional de Chile, 2018: 879).

El senador Araya aclaró que el objetivo de este plazo de seis meses es:

Evitar que exista un limbo en cuanto al tiempo, en el sentido de que no haya ningún tipo de pronunciamiento de parte de la Fiscalía. Lo que se busca con este plazo es dar certeza de cuándo se inicia la acción penal (Biblioteca del Congreso Nacional de Chile, 2018: 896).

Pero, ¿qué ocurriría si es que transcurre este plazo de seis meses sin que el fiscal nacional económico tome la decisión? Ante ello, es claro que habrá un incumplimiento grave de funciones por parte del fiscal nacional económico, que puede llevar una responsabilidad administrativa del mismo e, incluso, su destitución por la causal establecida en el artículo 33, letra c), del Decreto Ley 211, es decir, por negligencia manifiesta en el ejercicio de sus funciones.

\section{Regulación de la delación compensada}

Como se ha señalado en múltiples ocasiones durante este trabajo, uno de los ejes articuladores a partir de los cuales se efectuó todo el diseño normativo e institucional del nuevo título V del Decreto Ley 211 fue la delación compensada: La existencia de un doble filtro institucional y de una secuencialidad jurisdiccional fueron medidas que buscaron dar una adecuada protección al funcionamiento de esta, con el fin de lograr que la criminalización refuerce el funcionamiento de la delación compensada, profundizando los costos y así los incentivos a delatarse, sin mermar la eficacia de la misma.

El nuevo artículo 63 del Decreto Ley 211 establece la exención de responsabilidad penal con respecto a aquellas personas que primero hayan aportado antecedentes a la FNE en conformidad al artículo 39 bis. Para esto, el requerimiento del fiscal na- 
cional económico debe individualizar a estas personas beneficiadas, debiendo, para proceder la exención, ser declarados como beneficiarios de la exención por el TDLC en el fallo respectivo. Para los segundos delatores, es decir, quienes aporten a la FNE antecedentes adicionales en conformidad con el inciso cuarto del artículo 39 bis, se les rebajará la pena determinada en un grado. Estas personas también deben ser individualizadas por el fiscal nacional económico en su requerimiento y la calidad de beneficiarios también debe ser establecida por el TDLC.

\section{Discusión previa: ¿Es compatible la delación compensada con la criminalización?}

Como se ha esbozado a lo largo de este trabajo, parte de la doctrina comparada y nacional ha señalado que la criminalización de la colusión no solo implicaría una pérdida de eficacia de la delación compensada (Pellegrini, 2015: 4), sino que derechamente serían incompatibles ambos conceptos, ya que no sería posible sostener, por un lado, que se debe condenar por medio de la reacción más enérgica del sistema y, por otro, que se debe dejar libre a ese mismo sujeto solo por aportar antecedentes que permiten descubrir una colusión. Es decir, «habrían mensajes conflictivos que inevitablemente deterioran la capacidad de la ley penal de educar al empresario y al público en general, con respecto a qué conductas merecen condena y por qué» (Beaton-Wells, 2017: 147), lo que generaría un «sentimiento de indignación moral $y$, en última instancia, la pérdida de apoyo y credibilidad en el sistema, que parece premiar a ofensores graves, que se benefician con una sanción reducida o incluso con total inmunidad» (Harding, Beaton-Wells y Edwards, 2015: 245).

Desde el punto de vista del mensaje enviado al ciudadano, el problema sería que la coexistencia de ambas herramientas, generaría en él la siguiente respuesta:

Primero nos dicen que estas personas son tan malas como un delincuente violento, que merecen una sanción privativa de libertad de hasta diez años, y después tratan a algunos de ellos como amigos e incluso los premian de muchas maneras, cuando nos los presentaron como peligrosos traidores (Harding, Beaton-Wells y Edwards, 2015: 248).

Todavía más allá, estos autores críticos de la compatibilidad entre la delación compensada y la persecución penal de los carteles sostienen que el efecto del uso de ambas es que la delación compensada:

Opera como una desviación del proceso completo del juicio penal, privando a: a) cortes y jurados de la oportunidad de probar la suficiencia y probidad de la evidencia; b) jueces del poder de considerar las sanciones apropiadas tanto con fines retributivos como disuasivos; c) los acusados de la oportunidad de dar cuenta al resto del mundo de su participación en el asunto; d) al resto del mundo de la oportunidad de tener una visión completa e informada del caso; e) la capacidad de la ley penal en su 
rol de liderar y moldear la opinión pública (Harding, Beaton-Wells y Edwards, 2015: 248 y 249 ).

Por último, sostienen que «las políticas de clemencia, por naturaleza, refuerzan e incluso promueven las cualidades del engaño y la trampa que fueron las que llevaron a volver ilegal esa conducta en un primer momento» (Harding, Beaton-Wells y Edwards, 2015: 250).

Estos comentarios no deben entenderse como argumentos que impidan la compatibilización de la delación compensada y la persecución penal. Como fue visto, todas estas críticas se enmarcan en sociedades que no consideran moralmente condenable los acuerdos colusorios y, en ese sentido, la crítica se refiere a que la legislación penal del Reino Unido busca infundir un estigma moral en la sociedad del Reino Unido, pero al mismo tiempo permite que bajo ciertas circunstancias queden sin pena, lo que generaría reacciones contradictorias en ciudadanos que no condenan enérgicamente los carteles. Como se analizó, ese contraste entre el sentimiento colectivo y la «intención» normativa es del todo ajeno a la realidad chilena.

En ese contexto, el sistema incorporado, lejos de enviar mensajes contradictorios, lo que busca transmitir es que, entendiendo que la sanción penal es necesaria por la gravedad de la conducta, y su significado social, dicho castigo no se puede realizar afectando la principal herramienta para desbaratar carteles: la delación compensada. Buscar sancionar sin más solo llevará a que no se descubran más carteles, y eso es contraproducente para todos.

Así, al menos en el panorama chileno, la delación compensada y la persecución penal pueden ser compatibles, y la pretensión de la Ley 20.945 fue que esa sanción venga a reforzar un sistema tanto técnico como especializado que ha sido exitoso, manteniendo la herramienta investigativa y probatoria más eficiente e incorporando, por medio del establecimiento de una sanción penal, un vehículo transmisor de «una reacción estatal expresiva de desaprobación e indignación en contra de la o las personas a las cuales les resulte imputable la realización de esa misma forma de comportamiento» (Mañalich, 2015: 5) y, a juicio de algunos, añadiendo un medio de «incremento de la efectividad de la prevención general» (Gorab y Nehme, 2015: 11) en cuanto «la sanción penal tiene un alto poder disuasivo» (González, 2015: 10 ; Wils, 2005: 31 y 37). Además, la sanción penal, para parte de la doctrina, lejos de complicar la efectividad de la delación compensada, "contribuye a aumentar los incentivos para delatar el cartel reforzando la eficacia de la delación compensada» (Gorab y Nehme, 2015: 11). Para nosotros, los argumentos de mayor validez para sostener la criminalización vienen de nociones del retribucionismo consecuencialista, ya que no existe evidencia suficiente para alzar la pena privativa de libertad como un disuasivo, incluso en la comisión de delitos de costo-beneficio como estos. Mientras dicha evidencia no sea cierta y comprobable, el rol de la disuasión es compleja de medir: si no 
se descubren nuevos carteles luego de la introducción de una arista penal, bien puede ser que ello se deba al triunfo del rol disuasivo o a la inutilización de la delación compensada y, por tanto, a la incapacidad del sistema de descubrir los carteles. Esta discusión se ha dado en Australia, sin saber si es un éxito de la disuasión o un fracaso de un sistema mal diseñado (Beaton-Wells, 2017: 131).

A mayor abundamiento, parece complejo y cuestionable categorizar la delación compensada solo como un «premio» (Harding, Beaton-Wells y Edwards, 2015: 248.). Más bien, el objetivo de esta herramienta «es desestabilizar los carteles: habrá menos incentivos para asociarse con otros en colusión cuando exista el riesgo de que uno de los miembros del acuerdo confiese su participación» (Gorab y Nehme, 2015: 11), y puede entenderse que habrá más incentivos para confesar la participación cuando el riesgo de no hacerlo es una sanción más gravosa y no traspasable a terceros.

\section{¿Por qué la delación compensada?: Elementos que la vuelven imprescindible para una efectiva lucha contra la colusión}

Como se ha mencionado en más de una ocasión, la implementación de una sanción penal en los casos de colusión:

Debe ser compatible con la delación compensada [...]. Esta herramienta ha probado ser muy efectiva para descubrir carteles y cualquier ambigüedad con respecto a la concesión del indulto afectará negativamente los incentivos de las empresas a delatar su participación en ellos (Gorab y Nehme, 2015: 11).

El proceso de delación compensada, regulado en los artículo 39 bis y 63 del Decreto Ley 211, establece la posibilidad de eximir de responsabilidad penal y de disminuir la multa a las empresas involucradas en un acto de aquellos descritos en el artículo 3 , letra a), del mismo cuerpo normativo cuando proporcionen antecedentes precisos, veraces y comprobables que puedan constituir prueba suficiente para la interposición de un requerimiento, manteniendo la parte que solicita acogerse a este beneficio, una confidencialidad absoluta con respecto a la existencia del mismo, y siempre y cuando ponga fin a la conducta colusoria. Es decir, bajo un sistema «basado en el modelo de la teoría de juego conocido como dilema del prisionero» (Beaton-Wells, 2017: 127) se establece un sistema que «se justifica sobre la base de que son el mecanismo más efectivo y menos costoso para detectar y perseguir una actividad que generalmente es sistemática, deliberada y encubierta» (Beaton-Wells, 2017: 127), que cumple su función «incentivando una carrera para confesar» (Jones y Williams, 2014: 101).

Desde 2009, esta herramienta ha permitido descubrir la existencia de múltiples carteles en nuestro país, demostrando ser un sistema que, compatibilizando la incertidumbre propia de la colusión y los incentivos para la denuncia, ha logrado provocar que los propios involucrados revelen la existencia del cartel para beneficiarse con 
la exención de multa ante el temor de que la otra parte involucrada en la colusión solicite acogerse al beneficio antes que ella. Junto con ello, y como uno de los requisitos para que proceda la delación compensada es justamente que la parte solicitante otorgue información que sea precisa, veraz y comprobable, este mecanismo también ha permitido que la FNE obtenga toda la información que requiere para probar la existencia de la colusión en sede infraccional, y lograr la sanción pecuniaria a las empresas involucradas. Es en esa doble función donde radica su importancia vital para el éxito del proceso.

Fruto de todo lo anterior, el tema fundamental a ser resuelto por el legislador fue cómo compatibilizar el reproche jurídico democrático a la conducta con la necesidad de resguardar el adecuado funcionamiento de la delación compensada.

Bajo esos estándares de decisión, el legislador optó por establecer la secuencialidad de procesos judiciales, permitiendo que la delación compensada siga operando con normalidad en el proceso infraccional sin que se vea afectada por la existencia de un proceso paralelo penal iniciado por el Ministerio Público, ya que el logro de los fines de la delación compensada solo es posible si este proceso se lleva a cabo con suma confidencialidad y resguardo de información, y si a los delatores les es previsible la exención de la sanción, lo que debe estar prefijado con sumo detalle en la legislación, ya que de lo contrario el costo de delatarse es mayor que el beneficio de hacerlo.

Así, el legislador optó —en este punto- por introducir la sanción penal de la colusión con cautela, aunque valiéndose de la problemática tipificación de un delito de peligro abstracto, como ya fue analizado. El fundamento de este diseño institucional es legítimo y es claro: No olvidar que el objetivo final de toda regulación en la materia es y debe ser impedir la creación de acuerdos colusorios, y descubrir, desestabilizar y sancionar los ya existentes, pudiendo incluir en esas sanciones aristas penales, pero sin que eso implique dejar de descubrirlos y desbaratarlos. Esta necesidad de cautela se aprecia con claridad al analizar las experiencias comparadas en la materia.

Por ejemplo, uno de los principales problemas que se han generado en el Reino Unido es que no se estableció la secuencialidad entre el proceso infraccional y el proceso penal. Esto implica la existencia de procesos paralelos, que impiden una adecuada previsibilidad del asunto desde el punto de vista del potencial delator, con el riesgo que esto supone para la eficacia de la delación compensada (Jones y Williams, 2014: 100)

En el caso australiano, a pocos años de la instauración de un sistema que combina persecución penal e infraccional, la preocupación doctrinaria ha estado puesta justamente en lograr una adecuada compatibilización entre la persecución penal y la delación compensada, ya que desde que se criminalizó la colusión en este país, el número de solicitudes para acogerse a la política de clemencia disminuyó sin saber si celebrarlo o preocuparse por ello (Beaton-Wells, 2017: 131). 
Junto con esto, en ese país también se plantea que es imperativo que un sistema de lucha contra los carteles sea capaz de compatibilizar la eficacia probada de las políticas de clemencia con la persecución penal de los responsables. Lo anterior no por capricho, sino porque la existencia de herramientas como la delación compensada «es importante, incluso esencial, para asegurar que quienes se coluden sean generalmente atrapados y castigados como criminales» (Beaton-Wells, 2017: 140).

Este conjunto de particularidades de la lucha contra la colusión fue apreciado por el legislador chileno, que aun cuando sí se valió del derecho penal con ciertos fines simbólicos, lo cierto es que también lo contrapesó con criterios técnicos, todo lo cual se tradujo en un nuevo artículo 64 que estableció el diseño institucional ya desarrollado. Así, en la extensa discusión que se dio en el Senado se consideró como punto central que:

No hay que perder de vista que todo este esfuerzo se basa en la idea de que se buscan los mejores medios para desbaratar carteles y llevar a sus responsables ante la justicia, y que la experiencia nacional e internacional demuestran que la mejor manera para lograr este resultado es proteger la delación compensada (Biblioteca del Congreso Nacional de Chile, 2018: 677).

El punto central, por tanto, es que la inclusión de la arista penal no podía afectar la certeza con la que debe contar el delator a la hora de presentar su solicitud. Actualmente, el éxito de la delación compensada se debe en buena medida a que si el delator acude a la FNE a presentar su solicitud y esta agencia aprueba la solicitud, el TDLC no va a poder alterar el beneficio. Por tanto, la razón de ser de la secuencialidad jurisdiccional y de la radicación de la acción penal en manos de la FNE, en el fondo, es no afectar esa certeza, estando mandatada la justicia penal a respetar la exención o rebaja que fue determinada en un primer momento por la FNE. En relación con esto, deben llamar a la preocupación hechos como los ocurridos a fines de 2017 cuando el Consejo de Defensa del Estado interpuso una querella por el delito reiterado de estafa en contra de los ejecutivos laboratorios Fresenius Kabi Chile Ltda, Sanderson S.A y Biosano S.A., estando pendiente el proceso en sede infraccional (el requerimiento de la FNE es de agosto del mismo año), en el que el laboratorio Biosano S.A. se había acogido a la delación compensada. Hechos como este, a tan poco tiempo de la entrada en vigencia de la Ley 20.945, pueden minar fuertemente la eficacia de la delación compensada, ya que afectan la tan necesaria certeza a la hora de presentar la solicitud por parte del «delator» de que no serán perseguidos penalmente por esos mismos hechos bajo ninguna figura penal. 


\section{Conclusión}

Todo lo que hemos revisado nos permite dar luces sobre los principales aspectos en tensión a la hora de criminalizar la colusión, y nos permite efectuar una reconstrucción histórica de los argumentos jurídicos, políticos y económicos que están en el fondo del problema. Este ejercicio es sumamente relevante, ya que las pugnas subyacentes a esta discusión vuelven a aflorar cada cierto tiempo. En ese marco, este trabajo busca situar la discusión en un contexto y en un panorama argumentativo completo, con el objeto de tomar el peso a la complejidad del asunto y llamar la atención sobre la necesidad de legislar enserio en esta materia.

Para esto, este trabajo analizó, en primer lugar, las legítimas discusiones sobre la conveniencia de sancionar penalmente la colusión, y cómo esta se ha desarrollado en el debate doctrinario nacional y comparado, y en la discusión parlamentaria de la Ley 20.945. Actualmente, existen razones serias para sostener que la criminalización de la colusión es una opción válida desde un punto de vista retributivo, especialmente cuando se entiende que la pena expresa una reacción jurídica institucional ante el quebrantamiento de una norma de conducta socialmente significativa, con lo que una conducta paradigmáticamente lesiva como la colusión debe sancionarse con la reacción más enérgica del sistema jurídico penal. También se analizaron argumentos de índole disuasivo, frecuentes en doctrina nacional y extranjera, especialmente en delitos cuya razón de ser es un análisis costo-beneficio. Sin embargo, el carácter disuasivo de la pena privativa de libertad no ha sido aún comprobado, y en delitos como este es sumamente complejo saber si la falta de descubrimiento de carteles se debe a un efectivo rol disuasivo o a la incapacidad de descubrirlos.

Junto con eso, hemos analizado que el legislador optó por la introducción de un tipo penal en el artículo 62, que establece una penalización per se, entendiéndose este delito como uno de mera actividad (Gagliano y Aracena, 2018: 141) y de peligro abstracto al no ser necesario acreditar que el acuerdo confirió poder de mercado a los incumbentes. En este sentido, vimos que lo único que sanciona este tipo penal son los acuerdos expresos, excluyendo de su ámbito de tipicidad los acuerdos tácitos y las prácticas concertadas, ambos punibles en sede infraccional. Lo anterior se debe a fundamentos de previsibilidad probatoria, pero también a un afán de que lleguen a sede penal solo carteles duros y desnudos, afirmándose el tantas veces olvidado criterio de ultima ratio del derecho penal en el ordenamiento jurídico nacional.

Por otro lado, la introducción de una arista tan relevante y compleja como la persecución penal de conductas debe hacerse con suma cautela, especialmente considerando que toda incorporación en la legislación anticarteles debe efectuarse teniendo en consideración el rol de la delación compensada. Es esta consideración la que llevó al legislador a optar por un diseño normativo e institucional particular, estableciendo un requisito de un doble filtro institucional, en que es la FNE la encargada de ejercer 
la acción penal de manera exclusiva, teniendo el deber de hacerlo en aquellos casos «que comprometieren gravemente la libre competencia en los mercados» y estando facultados para ejercer la acción penal en el resto de los casos, debiendo justificar su negativa a accionar. Junto con esto, el legislador optó por exigir una secuencialidad jurisdiccional, siendo solo posible perseguir penalmente a las personas naturales involucradas en un acuerdo colusorio si es que su responsabilidad en el mismo fue establecida por sentencia firme y ejecutoriada del TDLC y/o de la Corte Suprema.

Analizamos, relacionado con lo anterior, cuándo debemos entender que una conducta «compromete gravemente» la libre competencia en los mercados, dilucidando el contenido específico de los criterios que deben ser tomados en consideración al determinar dicha gravedad.

Por último, analizamos el espacio que la nueva regulación otorgó a la delación compensada argumentando que en nuestro contexto es compatible esta con la criminalización, haciendo frente a las principales críticas teóricas y prácticas fundamentalmente esgrimidas en contextos sociales sustancialmente diferentes. Junto con esto, dedicamos un espacio considerable a explicar lo que actuó como eje articulador de la nueva legislación: qué es la delación compensada y por qué es tan importante resguardarla.

Lo medular de esta discusión es tener siempre presente que el objetivo de toda política criminal en esta materia es que los carteles se descubran y se desarticulen, evitando caer en consignas vacías que alcen a la persecución penal por sí misma como una herramienta para solucionar el conflicto, y potenciando mecanismos de desestabilización interna de los carteles, para evitar sus efectos nocivos en la sociedad. En ese marco, caer en la lógica actual de endurecer aún más las penas en algunos casos de colusión, del todo innecesario desde todo punto de vista, y volver a discutir el titular del ejercicio de la acción penal, solo desestabiliza el funcionamiento del sistema y nos pone un paso más lejos de descubrirlos.

\section{Referencias}

Agostini, Claudio (2015). «¿Cárcel para la colusión? Seis opiniones». Puntos de Referencia, 409: 2-4. Disponible en bit.ly/39TlAlq.

Araya, Fernando (2015). «La existencia de colusión explícita puede acreditarse por evidencia indirecta en ausencia de prueba directa. Una reflexión sobre colusión tácita, "acuerdos tácitos" y "prácticas concertadas". Corte Suprema, 29 de enero de 2015, rol 19806-2014». Revista Chilena de Derecho Privado, 24: 233-250. Disponible en bit.ly/3gw2lj2.

AreEdA, Phillip (1981). The rule of reason in antitrust analysis: general issues. Washington: Federal Judicial Center.

ArtaZA, Osvaldo (2017). «La colusión como forma de agresión a intereses dignos 
de protección por el derecho penal. Primera aproximación». Revista de Derecho (Valdivia), 30 (2): 339-366. Disponible en bit.ly/3n5GkKr.

BASCUÑán, Antonio (2015). «¿Cárcel para la colusión? Seis opiniones». Puntos de referencia, 409: 7-9 Disponible en bit.ly/3gv5pvI.

Beaton-Wells, Caron (2017). «Criminal Sanctions for cartel conduct; the leniency conundrum». Journal of competition law \& economics, 13 (1): 125-149. Disponible en bit.ly/2VXvsTo.

Beaton-Wells, Caron y Brent Fisse (2010). «Broadening the definition of collusion? A call for caution». Federal Law Review, 38 (1): 71-95. Disponible en bit.ly/2JN3syQ. Biblioteca del Congreso Nacional de Chile (2018). Historia fidedigna del establecimiento de la Ley 20.945. Disponible en bit.ly/2Wb2i33.

Browning, Edgar (1997). «A Neglected Welfare Cost of Monopoly-and Most Other Product Market Distortions». Journal of Public Economics, 66 (1): 127-144. Disponible en bit.ly/3qAYLc2.

Centro de Políticas PÚblicas UC (2017): «Sistema carcelario en Chile: Propuestas para avanzar hacia una mayor efectividad y reinserción». Temas de Agenda Pública, 93: 1- 19. Disponible en bit.ly/371fvBJ.

Dixon, Robert, Alan Gunther y Muhammad Mahmood (2001). «The Cost of Monopoly in Australian Manufacturing». The Australian Economic Review, 34 (4): 390-402. Disponible en bit.ly/3404IFI.

Fiscalía Nacional EConómica (2018). Guía interna para la interposición de querellas por el delito de colusión. Disponible en bit.ly/3gtInFA.

Gagliano, José Antonio y Pedro Aracena (2018). «Aproximación al tipo penal introducido por la Ley 20.945: Delito de colusión». Revista de Estudios de la Justicia, 29: 121-152. Disponible en bit.ly/30Gx7Zh.

GonzÁlez, Aldo (2015). «¿Cárcel para la colusión? Seis opiniones». Puntos de Referencia, 409: 9-10 Disponible en bit.ly/3gtHsVE.

Gorab, Daniela y Nicole Nehme (2015). «¿Cárcel para la colusión? Seis opiniones». Puntos de Referencia: 11-13. Disponible en bit.ly/3miLmX5.

GRUNBERG, Jorge (2017). «Los acuerdos y las prácticas concertadas como medios para cometer el ilícito de colusión y las colusiones Hub-And-Spoke». En Fiscalía Nacional Económica, reflexiones sobre el derecho de la libre competencia: informes en derecho solicitados por la Fiscalía Nacional Económica (2010-2017) (pp. 15-52) Santiago: Fiscalía Nacional Económica.

GrunberG, Jorge y Santiago Montt (2017). «La prueba de la colusión». En Fiscalía Nacional Económica, reflexiones sobre el derecho de la libre competencia: informes en derecho solicitados por la Fiscalía Nacional Económica (2010-2017) (pp. 305-386) Santiago: Fiscalía Nacional Económica.

Harding, Christopher, Caron Beaton-Wells y Jennifer Edwards (2015). «Leniency 
and Criminal Sanctions in anti-Cartel Enforcement: Happily Married or Uneasy Bedfellows?». Hart Publishing 12: 233-260. Disponible en bit.ly/39VwXZX.

Jones, Alison y Rebecca Williams (2014). «The UK response to the global effort against cartels: Is criminalization the solution?». Journal of Antitrust Enforcement, 2 (1): 100-125. Disponible en bit.ly/33SLK3Z.

JoshuA, Julian (2004). «Competition law enforcement. Criminalisation, cartels, leniency and class actions: a look into the future». Competition Law Insight 12/10/2004: 2-7.

LARRAURI, Elena (2000). La herencia de la criminología crítica. 2. ${ }^{a}$ ed. Madrid: Siglo XXI.

Larroulet, Pilar (2015). "Cárcel, marginalidad y delito». En Catalina Siles (editora), Los Invisibles. Porqué la pobreza y la exclusión social dejaron de ser prioridad (pp.157-194). Santiago: Instituto de Estudios de la Sociedad.

Levitt, Steven (1996). «The effect of Prison Population Size on Crime Rates: Evidence from prison overcrowding litigation». The Quarterly Journal of Economics, 111 (2): 319-351. Disponible en bit.ly/370VuLv.

MaÑalich, Juan Pablo (2015). «Retribucionismo consecuencialista como programa de ideología punitiva». InDret 2: 1-32. Disponible en bit.ly/37PXPrS.

Morales, Ana María y Sebastián Salinero (2020). «Fundamento Político-Criminal y Naturaleza Jurídica de las Penas Alternativas en Chile». Revista Chilena de Derecho, 47 (2): 513-541. Disponible en bit.ly/37SDEcV.

Plaza Pública Cadem (2016). Estudio 154. Disponible en bit.ly/3m2ydnB.

Pellegrini, Julio (2015). «¿Cárcel para la colusión? Seis opiniones». Puntos de Referencia, 409: 4-7. Disponible en bit.ly/37K6xrw.

Politoff, Sergio, Jean Pierre Matus y María Cecilia Ramírez (2003). Lecciones de derecho penal chileno. Parte general. Santiago: Jurídica de Chile.

Stephan, Andreas (2015). «Survey of Public Attitudes to Price Fixing in the UK, Germany, Italy and the USA». CPP Working Paper: 15-8. Disponible en bit.ly/2VZjeJq.

Sutherland, Edwin (1999). El delito de cuello blanco. Trad. por Rosa del Olmo. Madrid: La Piqueta.

TonRy, Michael (2008). «Learning from the Limitations of Deterrence Research», 37 Crime \& Just: 279-311. Disponible en bit.ly/2Kcm6jO.

VAldÉs, Domingo (2008). «Tipicidad y Regla per se en las colusiones monopólicas horizontales». Revista Anales Derecho UC: Temas de Libre competencia (2): 81-126. Disponible en bit.ly/33SJXvN.

Whelan, Peter (2012). "Legal Certainty and Cartel Criminalisation within the EU Member States». Cambridge Law Journal, 71(3): 677-702. Disponible en bit. ly/3m2lcn8.

-. (2013). "Cartel Criminalization and the Challenge of "Moral Wrongfulness"». Oxford Journal of Legal Studies 33 (3): 535-561. Disponible en bit.ly/37SBREJ. 
-. (2016). «Beyond the Theoretical: Articulating Enforcement Strategies for Successful European Antitrust Criminalization». Antitrust Law Journal 235, 81 (1): 235-270. Disponible en bit.ly/3n5rDqE.

WILs, Wouter (2005). «Is Criminalization of EU Competition Law the answer?». Remedies and Sanctions in Competition Policy Conference, Amsterdam Center for Law and Economics (ACLE): 1-52. Disponible en bit.ly/2ICqVT2.

\section{Sobre el autor}

Agustín Walker Martínez es abogado de la Universidad de Chile y ayudante del Departamento de Ciencias Penales y Criminología de la Facultad de Derecho de la misma casa de estudios. Además, es ayudante del Departamento de Ciencias Penales y Criminología de la Facultad de Derecho de la Universidad Andrés Bello. Su correo electrónico es awalkerm94@gmail.com. (D) https://orcid.org/oooo-0003-2468-6273. 
La Revista de Estudios de la Justicia es publicada, desde 2002, dos veces al año por el Centro de Estudios de la Justicia de la Facultad de Derecho de la Universidad de Chile. Su propósito es contribuir a enriquecer el debate jurídico en el plano teórico y empírico, poniendo a disposición de la comunidad científica el trabajo desarrollado tanto por los académicos de nuestra Facultad como de otras casas de estudio nacionales y extranjeras.

\author{
DIRECTOR \\ Álvaro Castro \\ (acastro@derecho.uchile.cl) \\ SITIO WEB \\ rej.uchile.cl \\ CORREO ELECTRÓNICO \\ cej@derecho.uchile.cl \\ LICENCIA DE ESTE ARTÍCULO \\ Creative Commons Atribución Compartir Igual 4.o Internacional
}

La edición de textos, el diseño editorial y la conversión a formatos electrónicos de este artículo estuvieron a cargo de Tipográfica

(www.tipografica.io) 